\title{
Functional caption literacy development through intra-formal L2 viewing
}

\section{Antonie Alm}

Universidad de Otago

mail: antonie.alm@otago.ac.nz

ORCID: https://orcid.org/0000-0002-1232-9204

\author{
Yuki Watanabe \\ Universidad de Otago \\ mail: yuki.watanabedotago.ac.nz \\ ORCID: https://orcid.org/0000-0003-2708-9191
}

\begin{abstract}
Drawing on the digital literacies framework developed by Pegrum et al. (2018), this article proposes that caption literacy, a form of multimodal literacy, enhances the learning experiences of language learners who engage in self-directed second-language viewing. It presents a pedagogical approach referred to as intra-formal learning, which enables students in educational settings to build on previous digital learning experiences, such as watching Netflix TV series in a foreign language. Prior knowledge is extended through guided exploration of learning options (including caption use) and interaction between students who are encouraged to reflect on and share their learning experiences. This study investigates the developmental processes during the seven-week-long intervention. The development of functional caption literacy, going beyond the mechanical ability of operating subtitles, represents a critical ability for learner-viewers as it enables them to optimise viewing options in accordance with their processing capacities and preferences within their social context.
\end{abstract}

Keywords: caption literacy, intra-formal learning, L2 viewing

\section{El desarrollo de la alfabetización funcional de los subtítulos por medio de la visualización intraformal de L2}

\section{RESUMEN}

Basándose en el marco de las alfabetizaciones digitales desarrolladas por Pegrum et al. (2018), este artículo propone que el aprendizaje del uso de subtítulos, una forma de alfabetización multimodal, mejora las experiencias de aprendizaje de los estudiantes de idiomas que participan en la visualización auto dirigida de una segunda lengua. Esto presenta un enfoque pedagógico denominado aprendizaje intraformal, que permite a los estudiantes en entornos educativos basarse en experiencias de aprendizaje digital previas, como ver series de televisión de Netflix en una lengua extranjera. Los conocimientos previos se amplían a través de la exploración guiada de las opciones de aprendizaje (incluido el uso de subtítulos) y la interacción entre los estudiantes, a los que se anima a reflexionar y compartir sus experiencias de aprendizaje. Este estudio investiga los procesos de desarrollo durante las siete semanas de intervención. El desarrollo de la literacidad funcional de los subtítulos, que va más allá de la capacidad mecánica de manejarlos, representa una capacidad fundamental para los estudiantes, ya que les permite optimizar las opciones de visualización de acuerdo con sus capacidades de procesamiento y sus preferencias, dentro de su contexto social.

Palabras clave: alfabetizaciones digitales, aprendizaje intraformal, visualización. 


\section{Introduction}

Video and subtitles have long been popular components for language learning. Primarily used in formal educational settings, most of the research on L2 viewing tends to analyse the cognitive impact of subtitle use on listening comprehension and lexical development (Gass et al., 2019; Guichon \& Cohen, 2016; Mitterer \& McQueen, 2009; Montero Perez et al., 2013; Szarkowska \& Gerber-Morón, 2018). Little is known so far on how language learners handle subtitles when they access video content in their second language and make their own selections. As film and TV series are increasingly easy to access through the availability of subtitles in the learner's first (L1) or second (L2) language, a new research area is emerging, investigating the ability of language learners to use subtitles to enhance comprehension and L2 learning as well as enjoyment of L2 video content.

This article introduces and discusses the concept of caption literacy, subsumed as multimodal literacy in the revised version of Pegrum et al.'s (2018) framework of digital literacies. It proposes that the ability to use L1 subtitles and captions (L2 subtitles) effectively for language learning requires specific digital literacy skills, the technical or mechanical skill of locating and activating captions, and the functional skill of adopting viewing strategies with captions that are needed by individual learners to optimise their learning and viewing experience.

\section{Digital literacies}

In the 1950s, when the term literacy was first operationalised by UNESCO, it was described, as quoted by literacy scholar Venezky, as "a continuum of skills, including both reading and writing, but applied in a social context" (1990, p. 4). The concept of literacy, however, can be traced further back. Cicero used the term literatus to describe a learned person. In the Middle Ages, it referred to the ability to read Latin. The skill of writing, which before the advent of quills required "technical exercise, involving instruments, muscular gymnastics, and a knack" (Furet \& Ozouf, 1982, as cited in Venezky, 1990, p. 3), only emerged after the Reformation. By that time, the notion of literacy extended to the ability to read and write in one's native language. The changing definitions of the term and of what it represents for a person to be literate or illiterate illustrate the situatedness of literacy, shaped by the social conditions and technological advances of their time. As quills and parchment have given way to pen and paper, and more recently to digital tools, the concept of literacy has taken another turn. Digital literacies - now implying plurality of technical and social skills - encompass an "ensemble of skills", as explained by Pegrum et al. (2018) "needed to effectively manage meaning in an era characterised by digitally networked communications, including blended communications that exploit both analogue and digital channels, often facilitated by mobile devices" (p. 462). A digitally literate person has, according to Dudeney \& Hockly (2016), the "ability to effectively make use of the technologies ... [and] an awareness of the social practices that surround the appropriate use of new technologies" (p. 115).

The implications of this shift, particularly in the last 20 years, are significant for tertiary foreign language education, which is informed by literacy practices of its time. Asheim's (1987) distinction of literacy skills from a pre-Internet world - of lower-level or pragmatic literacy and functional or cultured literacy "to read Faulkner and Wittgenstein" (Venezky, 1990, p. 3) - reflects traditional approaches to language learning based on language textbooks at lower levels (pragmatic literacy), and aiming for literary knowledge (cultural literacy) at higher levels. As the literacy skills of the $21^{\text {st }}$ century have adjusted to new social and technological contexts, language education has adopted new content (including video) and diversified communication channels. Further, as digital tools have not only transformed the communication channels but also the interaction patterns through those channels, access to foreign languages has expanded beyond national borders, and classroom walls and the boundaries between formal and informal language use have softened.

The digital literacies framework developed by Dudeney et al. (2013) takes these transformations into account, proposing in its revised form (Pegrum et al., 2018) four categories focusing on communication, information, collaboration, and (re-) design. Itemised by levels of complexity, print, a communication literacy, aligns with traditional notions of literacy, defined by Pegrum (2021) as "the ability to comprehend and create a variety of written texts, encompassing a knowledge of grammar, vocabulary, and discourse features alongside reading and writing skills" (np). On the other end of the spectrum is critical literacy, which includes the "ability to evaluate, appreciate and critique the implications of mobile communication for humanity" (np). Digital literacies research in language education highlights the interconnectedness of literacy skills from the four categories. For instance, digital forms of the second language (L2) communication in formal settings are largely informed by print literacies, yet they invoke personal, participatory, and intercultural literacy skills, as shown for example in studies Alm (2009) conducted on L2 blogging, Mills (2011) on L2 social networking and Hauck et al. (2016) on online learning communities.

The continuum of digital literacies presented in Pegrum et al.'s (2018) framework illustrates the complexity of skills involved to be literate in the current social context. A literate person in the $21^{\text {st }}$ century is not only able to consume information but also to prosume, that is to participate in and to shape or even create new digital practices (Manches \& Plowman, 2017; Thomas et al., 2013; Tofler, 1980). In the context of multimodal literacy, this represents "the ability to effectively interpret and create texts in multiple media, notably using images, sounds, and video" (Pegrum, 2021, $\mathrm{np}$ ), and in relation to captions, the ability to process or to produce captions. This ability is not necessarily taught in schools, as traditional literacy skills of reading, writing, and interpreting (cf. Asheim, 1987), although some digital literacy scholars see it as the prerogative of education to prepare and guide students through this process. Described as "tech comfy" rather than "tech-savvy" (Sansone, 2008, as cited in Pegrum, 2014, p. 200), educators often see learners as ill-equipped to deal with academic literacy requirements in formal settings. Hauck and Kurek (2017) argue that "educators need to become key players in shaping their students' attitudes and practices through purposeful selection and use of technology-based tools, tasks, and environments" (p. 1). The lines of tension between educators and students observed by Jones (2014) - between educators who are frustrated by learners' lack of critical thinking and students who are frustrated by teaching approaches of a pre-digital world - can only be overcome if educators are digital literat $i$ themselves. This includes openness to adopt learning formats informed by emerging digital practices and preparedness to involve learners in this process of knowledge construction.

An intra-formal approach to language learning (Alm, 2019) addresses this issue. This approach draws on learners' prior use of digital tools for language learning in informal contexts, considering both technical skills and digital cultures-of-use (Thorne, 2003). Learners are encouraged to extend and share their knowledge, providing support to each other and enriching the formal learning experience, which facilitates dialogic exchanges and guides the 
learning process. In the context of this study, this means drawing on learners' knowledge and use of Netflix and subtitles, both for L1 and L2 viewing, and considering their preferences before additional approaches and resources are introduced.

\section{Caption literacy}

Reading captions is a literacy skill already mentioned by Venezky (1990). He points out that reading captions differs from reading text passages as the reader must adjust to the speed of continuously appearing and disappearing lines. In addition, the reader must be able to process images and sound which he suggests may interact in "non-obvious ways" (p. 11), paving the way to an understanding of multimodal literacy. The benefits of reading subtitles for literacy development have been demonstrated in studies on reading skills in countries that subtitle rather than synchronise foreign language TV programmes (Bravo, 2008; Orrego-Carmona, 2015). The familiarity with subtitles can positively affect language awareness (Neves, 2004), and encourage language learning (Almeida \& Costa, 2014). As the international distribution of video content expands, the supply of and demand for captions has risen. Even in domestic media markets, partial captioning for native speakers (also called impact captioning), to emphasise funny remarks is now widely used in prime-time entertainment shows in Japan and Korea indicating that the ability to process captions has become part of functional adult literacy (Watanabe, 2006).

Caption familiarity has been reinforced through current practices on social media. For example, it has been estimated that $85 \%$ of all Facebook videos are viewed without sound (Onorato, 2018). The social networking site provides a feature for users to create captions to reach their audience. Similarly, viewers can activate auto-generated subtitles on YouTube to read along or to read instead of listening.

Caption automation, and the more widespread use of captioned videos for accessibility, has also enabled the development of language learning tools which provide video with captions, such as the Chrome extension used in this study, Language Learning with Netflix. The extension provides both captions as well as subtitles, with a choice of human or computer-generated translations.

The familiarity with captions in their L1 suggests that language learners are better equipped to process bi-modal input (listening and reading) or at least be more receptive to using captions for L2 video content. The advantages of captions to support comprehension and vocabulary acquisition through inbuilt redundancy are pointed out by Pegrum (2019). However, he also draws attention to the challenges that multimodal input represents for language learners, especially if additional tools (such as subtitling or vocabulary extensions) are involved.

\section{Captions for language learning}

The benefits of captions for L2 viewing and language learning development are well established. In the early 2000s, King (2002) observed an increasing interest in closed-captioned materials as DVDs became readily available for classroom use. Unlike VHS tapes, some DVDs provided intralingual subtitles, developed for the deaf, or hard-of-hearing, but equally beneficial for language learners. According to King (2002), closed-captioned video can help language learners to:

- follow a plot easily and get involved in plot development

- $\quad$ recognise words pronounced with different accents

- $\quad$ acquire colloquial, context-bound expressions and slang
- $\quad$ process a text rapidly and improve rapid reading

- $\quad$ keep up with closed captioning that accompany the native-speed spoken English

- $\quad$ provide relaxing, stress-free learning environments where students can comprehend jokes and have a few hearty laughs

- $\quad$ learn different strategies for processing information (pp. 516-517).

Reinforced and refined by subsequent caption research, King's observations relate to literacy both in its conventional conception and in the context of digital literacies. She stresses that subtitles can support the development of reading skills, as caption speed pushes learners to read fast and skilfully (Randev, 2014; Venezky, 1990). However, the learner's ability to process written, oral and visual information and to use different strategies for processing information involves multimodal literacy skills.

Processing information presented via captioned video involves an ensemble of skills (Pegrum, 2018), namely listening to spoken language as well as reading written texts on screen while seeing moving images in the background. Findings from previous studies indicate that these skills can be integrated and recruited to enhance language learning. For example, the presence of written text on the screen can help learners focus on the language and engage in active viewing through pausing, rewinding, re-watching, writing down new vocabulary, and reviewing (Vanderplank, 2016). Written texts with speech and image can work to compensate for what one misses in one channel, resulting in better recognition of known words as well as the acquisition of new words by providing simultaneous access to the spelling via text, pronunciation via sound and meaning via the integration of sound, text, and image (Bravo, 2008; Price, 1991; Sydorenko, 2010; Vanderplank, 2016; Wisniewska \& Mora, 2020). A better understanding of "plot, characters, complicated dialogue, rapid speech and accents" (Vanderplank, 2016, p. 218) with the aid of captions makes the viewing experience more enjoyable. The literature also suggests some obstacles learners experience as they adjust their cognitive capacities from single modal to multimodal sources of information. These include overload in one's visual channel due to an extra layer of information on the screen, which in some cases leads to caption dependency where learners focus on reading captions and shut down the processing of other available information input (Ayres \& Sweller, 2014; Vanderplank, 2016).

\section{Caption-based language learning with Netflix}

The language and subtitle options available on Netflix enable learner-viewers to make a range of viewing choices. Subbing and dubbing options have been introduced to make the content available to an international audience, whereas other features, such as closed captions, audio descriptions, and more recently playback speed control increase accessibility. Closed captions include descriptive in addition to the spoken text for the deaf and hard-ofhearing. Similarly, audio descriptions include physical actions, facial expressions, costumes, settings, and scene changes for the visually impaired. Reducing the speed can help those who are not able to follow subtitles at regular speed.

So far, there are only a few studies of Netflix for language learning with a focus on subtitling use and effectiveness. Within a formal learning context, Dizon (2016) compared intermediate-level Japanese EFL learners' responses to the use of L1 subtitles, L2 subtitles, and no subtitles using American TV shows available on Netflix. Students selected three shows which were then viewed in class in the three subtitle modes. L2 subtitles were favoured over subtitles in the students' first language or no subtitles, sug- 
gesting that the learners did not want to rely on their L1, but also did not have the proficiency needed to view the video without subtitles. In a further study, Dizon (2018) provided nine Japanese EFL students with free access to Netflix for three months to find out how language learners use the resource in their own time without formal instruction. Most comments collected under the theme of learning effectiveness referred to the benefits of subtitles for comprehension and vocabulary learning. In being able to choose their preferred subtitle option, a new variation emerged: the combined use of subtitles and captions to adjust to varying levels of difficulty encountered in specific viewing situations. The dynamic use of subtitles and captions adds a twist to caption studies in formal settings, comparing the effectiveness of L1 vs. L2 vs. no subtitle viewing conditions (Dizon 2016; Markham et al., 2001) and is recently extended with the reversed subtitle option (Kim, 2020). The dual use of subtitles and captions for out-of-class L2 viewing was also observed in Alm's (2021) pilot study. She found that some students used both German and English subtitles, either to look up words or phrases or, using a "sandwich" approach, playing sequences three times (changing subtitles from German to English and back to German) to increase comprehension and retention. The use of the subtitling extension LLN has so far only been addressed in Türkmen's (2020) survey study. While the study does not include any details on the actual use of the tool for L2 viewing, it showed that $19.3 \%$ of participants were familiar with the extension. The aim of this study is to investigate the impact of LLN on the development of caption literacy among language learners in an intra-formal setting.

\section{Methodology}

\section{Participants}

The participants of this study are from two cohorts, intermediate level students of a German $(n=11)$ and of a Spanish class $(n=28)$. All students agreed to participate in the study and gave consent for their written work to be used for analysis. The names used in the study are pseudonyms.

\section{Instruments}

The data were collected by means of two questionnaire surveys, two follow-up interviews, and learner blogs. The pre-survey gathered data on the students' previous Netflix experiences to assist in interview planning and data analysis. The post-survey was administered at the end of the project to validate the data. Since the blogs were part of the language activity and written in the target language, they were translated into English for analysis. The interviews were conducted in English. To ensure the validity and reliability of the questionnaires, drafts of each survey were reviewed by two colleagues, one in applied linguistics and the other in mobile-assisted language learning. The revised questionnaires were piloted with 10 language students from the languages programme.

\section{Procedures}

During the first week of classes, the lead researcher visited both classes to introduce the project. Students who did not have access to Netflix were provided with a free account. In addition, they received instructions to install the Language Learning with Netflix extension on their computers. Both cohorts received the same instructions: they were asked to watch a Netflix series of their choice for seven weeks, with a minimum of three episodes per week. In addition, they had to write about their series in their weekly blogs and to comment on each other's viewing and learning experiences. A link to the pre-intervention questionnaire was emailed to all students. Once the data of the 24 received responses were collected and analysed, follow-up semi-structured interviews were conducted with 12 students in two focus groups. At the conclusion of the intervention, the blog entries were collected, translated into English, and imported into NVivo. A preliminary thematic analysis of the blogs informed the second round of interviews conducted on Zoom with 11 participants in four focus groups. The interviews were, like the previous interviews, transcribed with the transcription tool Otter and cleaned up by a research assistant. The interview data were then imported into NVivo to extend the thematic analysis. The analysis informed the design of the final online questionnaire which was taken by 22 participants.

\section{Data analysis}

The study utilised a mixed-methods research design and collected qualitative and quantitative data. NVivo 12 was used for thematic analysis of the translated data from the blogs and the interviews. The data were analysed for specific themes and the topics of the research question (Ellis \& Barkhuizen, 2005). To establish inter-rater reliability, the qualitative data were coded by the two authors, resulting in a Kappa value of .99. Responses to the 5-point Likert items from the questionnaire were analysed through IBM SPSS 25. The study utilised non-parametric tests to analyse the quantitative data as the sample size is small, and the data are not normally distributed (Grech \& Calleja, 2018). In particular descriptive statistics, Spearman rho correlation was utilised to analyse the quantitative data.

\section{Findings and discussion}

\section{L2 Netflix habits and caption use prior to the intervention}

With a preference for series (62.5\%) over movies (33.3\%), all but three participants were active Netflix users, watching between one to six hours of Netflix weekly for entertainment $(94.7 \%)$, to relax $(97 \%)$ or in the background while doing other things $(57.9 \%)$. Some participants indicated that they used captions while watching programmes in their L1 to increase comprehension or to avoid disturbing others with sound.

Regarding their experiences with Netflix in their L2, 73\% had already searched for L2 movies and series, and $68.4 \%$ had watched L2 Netflix for some time. This contrasted the $15.8 \%$ who had never thought of watching Netflix in their L2, possibly because it was considered too difficult. Spearman's rho revealed a statistically significant relationship between I thought of watching L2 series but considered it too difficult and Before the project I found it daunting watching NF in L2 as native speakers speak too fast (rs[19] = $.62, p<.001$ ). Subtitles were the most popular choice to overcome comprehension difficulties. Looking back on her L2 Netflix engagement prior to the project, Alisha commented,

For year 13 German I was getting less and less motivated ...

So I ended up watching Dark, but I just didn't think about it,

obviously, because I was a stupid year 13 student and I watched

it with English subtitles and just didn't concentrate on it at all.

Just as others who had not thought of using Netflix to apply or practice their language skills, Alisha had not thought about the benefits of using captions for her language development. In other words, familiarity with Netflix and caption literacy in 
their L1 provided students with a mechanical understanding of how to access L2 TV series. Subtitles were used as an aide for comprehension and were not perceived as distracting. With only $27.2 \%$ having used captions prior to the intervention, these findings suggest that most participants did not extend their existing digital knowledge to explore viewing options to improve their language skills.

\section{Exploring LLN - developing mechanical literacy}

Initially, none of the students were familiar with the LLN extension. They were introduced to the basic features - the use of dual subtitles, activation and deactivation of auto-pause (after each subtitle), and the dictionary and word-saving functions and asked to install and explore the extension in their own time.

The correlations between the questionnaire items suggest that two approaches among participants were used at this stage, to explore $(65.2 \%)$ or to ignore $(34.8 \%)$ the extension. These were associated with different initial experiences and behaviours to acquire knowledge about subtitling options. Spearman's rho revealed a statistically significant relationship between I explored the different features of LLN and I talked to my classmates about how they used LLN $(\mathrm{rs}[20]=.563, p<.001)$ and between I talked to my classmates about how they used LLN and Reading the blogs of others gave me some ideas on how to use LLN $(\mathrm{rs}[20]=.780, p<.001)$.

This suggests that those who explored LLN found it easy to use, but also drew on the knowledge of their peers by talking to them about their experiences or getting ideas in their blogs. In contrast, those who had problems getting LLN to work seemed to prefer a tutorial on how to use LLN. These participants were less likely to explore the options on LLN and less likely to talk to their peers or read in their blog about LLN. As suggested by Vanderplank (2016), interacting with peers is one of the essential features of successful language learning in informal settings, and students' willingness to acquire knowledge through peer interaction seems to be a factor associated with how likely their mechanical knowledge of the learning tool will be tried out and used for effective language learning.

Among the various features on LLN, dual subtitles, used by $95 \%$ of the participants, were not only the most popular, but for many also the only one they used. However, the ability to process dual subtitles varied among participants. While considered useful, dealing with dual subtitles was, as Emma put it, "not the easiest thing to $d o^{\prime \prime} .52 .17 \%$ of participants found it difficult to read both subtitles at once and had trouble keeping up with speed. About $31 \%$ of them also found them distracting, some to a point where they experienced cognitive overload in their visual channel (Ayres \& Sweller, 2014), as explained by Tony, "my eyes didn't know where to look. I couldn't read two simultaneously texts in different languages at the same time".

To deal with their processing difficulties, participants developed different approaches: some prioritised one mode of input over the others, for example, by focusing on listening and only glancing at the subtitles, or by focusing on reading the captions while only glancing at the subtitle. Some participants established a habit of sequencing listening and reading (first listen and then read captions, or first read captions and then listen). Clarissa, a self-proclaimed visual learner, "much preferred to read it first" and then listen. Others, like Mike and Mary, maintained that they were able to process all inputs simultaneously. They talked about their experience of "soaking in the screen". These experiences demonstrate the variability of participants' responses to dual subtitles, indicating that developing skills to deal with a new technological feature derives from individual preferenc- es and cognitive processing style (Caimi, 2006; Gass et al., 2019; Hwang et al., 2019).

The auto-pause feature was less popular (used by less than half, $45.9 \%$ ), as some felt that it broke the flow of the story. Yet manual pausing to read captions was a commonly adopted strategy to process the written input. Some paused systematically after each sentence, whereas others only when they missed a word or phrase. For example, Joe read the subtitles in Spanish, paused the program, and used the dictionary function when he did not understand a word. Rather than pausing, Alisha found the slowing down feature more helpful, using it especially when characters started talking fast. Alisha also found the hidden subtitle function and recommended it in her blog to her classmates. Clarissa picked up on her suggestion and found it equally "very helpful" as it reduced her reliance on subtitles.

Participants who tried additional features were also more likely to explore further features on LLN. Spearman's rho revealed a statistically significant correlation between those who used hidden subtitles and those who used slow down function $(\mathrm{rs}[20]=$ $.911, p<.001)$. The users of hidden subtitles are also more likely to have looked up words by activating the hidden English translation $(\mathrm{rs}[20]=.807, p<.001)$. This underscores the finding discussed earlier that those who explore different options are more likely to find LLN self-explanatory and thus more likely to try different features to figure out the optimal viewing strategy that works for them. The willingness to explore and try different features of LLN could be interpreted as positive attitudes toward the potential of captions and considered as one of the characteristics of "active users of captions" (Vanderplank, 2019, p. 416).

\section{Developing functional caption literacy}

The initial enthusiasm expressed by many participants about the availability of dual subtitles was followed by a sense of linguistic overload. Alisha reflected on her first encounter with LLN as "quite overwhelming" as she felt "there's so much German". Henry attributed the initial difficulty he had with LLN to the fact that he "was not used to reading the subtitles" when watching series on TV, confirming that prior experience with subtitles impacts upon the ability to process captions (Vanderplank, 2016).

Splitting attention among multiple modes of input was a challenge for several participants, but most developed strategies to overcome this difficulty. Clarissa explained that she started with just German subtitles and then switched to dual subtitles, so she did not have to pause after each sentence. Eric realised that the presence of subtitles made it difficult for him to focus on the language and started to use just the captions. As weeks progressed, participants started to acknowledge the benefits of LLN. Jane wrote in her blog that LLN helped her expand her vocabulary. Clarissa liked LLN as she could "listen and read in Spanish" and felt like she was "learning the language not just watching the series". Opal observed that she reduced her reliance of L1 subtitles and felt that her learning improved. Heidi recognised her increased awareness of commonly used colloquial phrases and improved comprehension of the story. Further into the project, students expressed increased confidence in using LLN and enjoyment of watching L2 shows on Netflix.

\section{Perceived benefits of captions}

Most participants agreed that captions helped them to focus better on the language $(86.95 \%)$ and with word recognition $(86.95 \%)$, the pronunciation of words $(73.9 \%)$, remembering words and phrases $(91.3 \%)$ and to enhance their understanding of the 
structure of spoken L2 (95.7\%). Spearman's rho revealed a statistically significant relationship between those who said $L 2$ subtitles allow me to focus better on the language and those who agreed I remember words and phrases better when I have L2 subtitles ( $\mathrm{rs}[20]=.656$, $p<.001$ ), as well as those who said L2 subtitles help me to understand the words better $(\mathrm{rs}[20]=.563, p<.001)$. These findings are consistent with studies suggesting that captions encourage students to engage in active viewing (i.e., focus on language) which will lead to better vocabulary learning (Gass et al., 2019; Montero Perez et al., 2013; Sydorenko, 2010; Vanderplank, 2016). These benefits of captioned video can be linked to multimedia learning theory which suggests two channels of inputs (audio and visual, compared to just audio) enhance learning (Mayer, 2014). Fiona acknowledged the advantage of having redundant input via captions: "You can always hear what the words actually are. So being able to read the Spanish, then I can match up the words that they're saying with the words that I'm reading, and it would all make more sense".

Correlations also show that better word recognition due to captions are linked to the perception of improved retention of words, better pronunciation and a better understanding of spoken L2, Spearman's rho indicating significant correlations in all instances. Participants also revealed that captions helped them recognise regional accents and vocabulary. Anna, who chose to watch 'Pablo Escobar' because of her interest in Colombian Spanish, wrote,

In 'Pablo Escobar, the Patron of Evil', there are many words that belong to Colombia, and that is why it is interesting to listen to the voice and see the comparison with the English subtitles. Sometimes some words are very different.

Similar observations were made in Mitterer and McQueen (2009) who found L2 subtitles assist recognition and retention of words presented in accented speech. These cases indicate subtitle and caption features of LLN work to expand the accessible material for language learners and enable them to follow their interest in language varieties in an intra-formal setting.

Some participants, however, remained unable to overcome processing difficulties to take advantage of the LLN features to optimise their learning and viewing experience, possibly due to their lower language proficiency. Issues with balancing listening and reading were mentioned by Heidi and Tracey. Heidi felt that visual engagement with subtitles compromised her capacity to process audio. Tracey said she had to focus "much more on reading the subtitles than listening to the dialogues". Nine percent of students expressed strong disagreement to the statement of L2 subtitles allow me to focus better on my listening, indicating that they were tied to just reading texts. This seems to be the case of caption dependency due to overload in visual capacity (Vanderplank, 2016). A few participants were irritated by inconsistencies, omissions, errors, and inaccuracies in the English subtitles. For example, Austin wrote, "the English words in the translations are very different compared to what they say in Spanish". Whereas more proficient language learners are able to deal with non-matching captions and even consider them as beneficial as they offer alternatives ways of expressions and synonyms, learners at lower levels do not seem to be able to process non-redundant multiple input (Vanderplank, 2016).

\section{L2 viewing confidence}

At the end of the seven-week period, most participants had gained the confidence to view Netflix series in their L2. While at the beginning of the project, $81.8 \%$ strongly or somewhat agreed that they found it daunting to watch an L2 programme, 95.4\% said they now felt confident watching L2 Netflix. This growth in confidence related primarily to their effective use of captions as their experience in viewing captioned videos contributed to a more balanced use of multiple sources of input (Gass et al., 2019; Kruger, 2013). Spearman's rho revealed a statistically significant relationship between With L2 subtitles I feel more confident watching an L2 series and When watching L2NF I mainly use L2 subtitles (rs[20] $=.593, \mathrm{p}<.001)$.

The survey confirmed that gains in confidence correlated with perceived improvement in listening and lexical developments, echoing earlier findings from Vanderplank $(1988,2016)$ and Dizon (2016). Spearman's rho revealed a statistically significant relationship between I have gained confidence watching L2NF and listening $(\mathrm{rs}[20]=.675, p<.001)$. and vocabulary $(\mathrm{rs}[20]=.600, p<.001)$. Correlations were also found between the areas of improvement, listening and vocabulary $(\mathrm{rs}[20]=.629, p<.001)$, and reading and pronunciation $(\mathrm{rs}[20]=.597, \mathrm{p}<.001)$. Mike commented during the interview that his vocabulary broadened through viewing "everyday conversations between native Spanish speakers". Alisha explained that by week six, she was able to "look away from the screen and just listen". Increased confidence in listening could not only be explained by increased vocabulary and familiarity (cf. Mary above) but also reflect a change in attitude and approach to $\mathrm{L} 2$ viewing. For Clarissa, listening became easier because she had become "less concerned about translating every word and instead trying to catch the main points of the sentence".

These developments, like those observed by Vanderplank (2016), the increase in L2 viewing confidence through captions, enabling learner-viewers to tune in and enjoy the L2 series, which in turn leads to a more dynamic use of subtitles and an increased ability to process listening and reading, which are all indicators of developing functional caption literacy. Learners became able to activate their declarative or mechanical knowledge about subtitle choices and further adjust them to the specific context of their viewing situation, determined by both internal (personal interest, physical state) and external (level of difficulty, interferences) factors.

\section{Conclusion}

This study on intra-formal L2 viewing has confirmed and extended previous research on the cognitive aspects of captioned-video processing. By conceptualising caption use in the context of digital literacies, it further addressed the "ability to effectively make use of the technologies ... [and] an awareness of the social practices that surround the appropriate use of new technologies" (Dudeney \& Hockly, 2016, p. 115). In this article, caption literacy is defined as the ability to effectively manage captions for L2 viewing. Distinguishing between a lower level and a higher level of caption literacy, mechanical caption literacy describes the ability to locate and activate subtitling options in an L2 viewing environment. In the context of this study, it applies to the ability to switch from L1 to L2 subtitles on Netflix and to navigate subtitling options on the Chrome extension LLN. Functional caption literacy, on the other hand, refers to the learner's ability to make subtitling choices that support identified viewing preferences and learning needs. Functional caption literacy implies that language learners use the captions option on Netflix or LLN confidently, resulting in learning gains.

\section{References}

Alm, A. (2009). Blogging for self-determination with L2 learner journals. In M. Thomas (Ed.), Handbook of research on Web 2.0 and second language learning (pp. 202-222). IGI Global. https:// doi.org/10.4018/978-1-60566-190-2.ch011 
Alm, A. (2019). Piloting Netflix for intra-formal language learning. In F. Meunier, J. Van de Vyver, L. Bradley \& S. Thouësny (Eds.), CALL and complexity - short papers from EUROCALL 201 (pp. 1-6). Research-publishing.net. https://doi.org/10.14705/ rpnet.2019.38.979

Alm, A. (2021). Language learning with Netflix: from extensive to intra-formal learning. The EuroCALL Review, 29(1), 81-92. https://doi.org/10.4995/eurocall.2021.14276

Almeida, P. A., \& Costa, P. D. (2014). Foreign language acquisition: The role of subtitling. Procedia-Social and Behavioral Sciences, 141, 1234-1238. https://doi.org/10.1016/j.sbspro.2014.05.212

Asheim, L. (1987). The reader-viewer-listener: An essay in communication. Library of Congress.

Ayres, P., \& Sweller, J. (2014). The split-attention principle in multimedia learning. In R. Mayer (Ed.), The Cambridge handbook of multimedia learning (pp. 206-226). Cambridge University Press. https://doi.org/10.1017/CBO9780511816819.009

Bravo, M. C. C. (2008). Putting the reader in the picture: Screen translation and

foreign language learning [Unpublished doctoral dissertation]. Universitat Rovira I Virgili, Tarragona, Spain. http://tdx.cat/ handle/10803/8771.

Caimi, A. (2006). Audiovisual translation and language learning: The promotion of intralingual subtitles. The Journal of Specialised Translation, 6, 85-98. https://jostrans.org/issue06/art_caimi. php

Dizon, G. (20160. Online video streaming in the L2 classroom: Japanese students' opinions towards Netflix and subtitles. Osaka JALT Journal, 3, 70-87. https://doi.org/10.4995/eurokal.2018.9080z

Dizon, G. (2018). Netflix and L2 learning: A case study. The EuroCALL Review, 26(2), 30-40. https://doi.org/10.4995/euroca11.2018 .9080

Dudeney, G., Hockly, N., \& Pegrum, M. (2013). Digital literacies. Routledge. https://doi.org/10.4324/9781315832913

Dudeney, G., \& Hockly, N. (2016). Literacies, technology and language teaching. In, F. Farr \& L. Murray (Eds.), The Routledge handbook of language learning and technology (pp. 115-126). Routledge.

Ellis, R., \& Barkhuizen, G. P. (2005). Analysing learner language. Oxford University Press.

Gass, S., Winke, P., Isbell, D. R., \& Ahn, J. (2019). How captions help people learn

languages: A working-memory, eye-tracking study. Language Learning E Technology, 23(2), 84-104. https://doi.org/10125/44684

Guichon, N., \& Cohen, C. (2016). Multimodality and CALL. In F. Farr \& L. Murray (Eds.), The Routledge handbook of language learning and technology (pp. 509-521). Routledge. https://hal. archives-ouvertes.fr/hal-01303401

Grech, V., \& Calleja, N. (2018). WASP (Write a Scientific Paper): Parametric vs. non-parametric tests. Early Human Development, 123, 48-49. https://doi.org/10.1016/j.earlhumdev.2018.04.014

Hauck, M., \& Kurek, M. (2017). Digital literacies in teacher preparation. In S. Thorne \& S. May (Eds.), Language, education and technology (3 ${ }^{\text {rd }}$ ed.). Encyclopaedia of Language and Education (pp. 1-13). Springer. https://doi.org/10.1007/978-3-319-02237-6_22

Hauck, M., Galley, R., \& Warnecke, S. (2016). Researching participatory literacy and positioning in online learning communities. In F. Farr \& L. Murray (Eds.), The Routledge handbook of language learning and technology (pp. 71-87). Taylor \& Francis. https://doi.org/10.4324/9781315657899.CH5

Hwang, G-J., Hsu T-C., \& Hsieh, Y-H. (2019). Impacts of Different smartphone caption/subtitle mechanisms on English listening performance and perceptions of students with different lear- ning styles. International Journal of Human-Computer Interaction 35(4-5), 333-344. https://doi.org/10.1080/10447318.2018.1543091

Jones, R. H. (2014). Digital literacies for language teachers: Beyond competencies. In H. P. Widodo \& N. T. Zacharias, (Eds.), Recent issues in English language education: Challenges and directions (pp. 117-140). UNS Press. http://llt.msu.edu/issues/ october2015/commentary.pdf

Kim, N.-Y. (2020). Languages on the screen. A study on reversed subtitling and EFL receptive language skills. Multimedia-Assisted Language Learning, 23(1), 37-66.

King, J. (2002). Using DVD feature films in the EFL classroom. Computer Assisted Language Learning, 15(5), 509-523. https://doi. org/10.1076/call.15.5.509.13468

Kruger, J-L. (2013). Subtitles in the classroom: Balancing the benefits of dual coding with the cost of increased cognitive load. Journal for Language Teaching, I47(1), 29-53. https://doi. org/10.4314/JLT.V47I1.2

Manches, A., \& Plowman, L. (2017). Computing education in children's early years. British Journal of Educational Technology, 48(1), 191-201. https://doi.org/10.1111/bjet.12355

Markham, P. L., Peter, L. A., \& McCarthy, T. J. (2001). The effects of native language vs. target language captions on foreign language students' DVD video comprehension. Foreign Language Annals, 34(5), 439-445. https://doi.org/10.1111/j.1944-9720.2001. tb02083.x

Mayer, R. (2014). Cognitive theory of multimedia learning. In R. Mayer (Ed.), The Cambridge handbook of multimedia learning (pp. 43-71). Cambridge University Press. https://doi.org/10.1017/ CBO9781139547369.005

Mills, N. (2011). Situated learning through social networking communities: The development of joint enterprise, mutual engagement, and a shared repertoire. CALICO Journal, 28(2), 345-368. https://www.jstor.org/stable/calicojournal.28.2.345

Mitterer, H., \& McQueen, J. M. (2009). Foreign subtitles help but native-language subtitles harm foreign speech perception. PLoS ONE, 4(1), e7785. https://doi.org/10.1371/journal. pone.0007785

Montero Pérez, M., Van Den Noortgate, W., \& Desmet, P. (2013). Captioned video for L2 listening and vocabulary learning: A meta-analysis. System, 41(3), 720-739. https://doi.org/10.1016/j. system.2013.07.013

Neves, J. (2004). Language awareness through training in subtitling. In P. Orero (Ed.), Topics in audiovisual translation (pp. 127-140). John Benjamins. https://doi.org/10.1075/btl.56.14nev

Onorato, A. (2018, March 4). Why you should add Facebook video captions (And how to do it). Idea Rocket. https://bit.ly/3rsKU7O

Orrego-Carmona, D. (2015). The reception of (non) professional subtitling. [Doctoral dissertation, Universitat Rovira i Virgili, Spain].

Pegrum, M., Dudeney, G., \& Hockly, N. (2018). Digital literacies revisited. European Journal of Applied Linguistics and TEFL, 7(2), 3-24.

Pegrum, M. (2014). Mobile learning: Languages, literacies and cultures. Springer.

Pegrum, M. (2019). Digital literacies in language education[Interview]. Matraga-Revista do Programa de Pós-Graduação em Letras da UERJ, 26(47), 462-469.

Pegrum, M. (2021). Digital literacies. https://markpegrum.com/ overview-of-digital-learning/e-learning-with-web-3-0/

Price, K. (1983). Closed-captioned TV: An untapped resource. MATESOL

Newsletter, 12(2), $1 \& 8$.

Randev, D. J. (2014). Reading all the way to functional literacy: Using same language subtitling in television programmes in 
India. IOSR Journal Of Humanities And Social Science, 19(7), 2429. https://doi.org/10.9790/0837-19772429

Sydorenko, T. (2010). Modality of input and vocabulary acquisition. Language Learning $\mathcal{E}$ Technology, 14(2), 50-73. http:// dx.doi.org/10125/44214

Szarkowska, A., \& Gerber-Morón, O. (2018). Viewers can keep up with fast subtitles: Evidence from eye movements. PloS ONE, 13(6), e0199331. https://doi.org/10.1371/journal.pone.0199331

Thorne, S. L. (2003). Artifacts and cultures-of-use in intercultural communication. Language Learning $\mathcal{E}$ Technology, 7(2), 38-67. https://doi.org/10125/25200

Thomas, M., Reinders, H., \& Warschauer, M. (2013). Contemporary computer-assisted language learning: The role of digital media and incremental change. In M. Thomas, H. Reinders \& M. Warschauer (Eds.), Contemporary computer-assisted language learning (pp. 30-47). Bloomsbury.

Toffler, A. (1980). The third wave. Bantam.

Türkmen, B. (2020). Utilising digital media as a second language (L2) support: A case study on Netflix with translation applications. Interdisciplinary Description of Complex Systems, 18(4), 459-470. https://doi.org/10.7906/indecs.18.4.6
Vanderplank, R. (2016). Captioned media in foreign language learning and teaching: Subtitles for the deaf and hard-of-hearing as tools for language learning. Palgrave Macmillan. https://doi. org/10.1057/978-1-137-50045-8

Vanderplank, R. (2019). 'Gist watching can only take you so far': attitudes, strategies and changes in behaviour in watching fil$\mathrm{ms}$ with captions. The Language Learning Journal, 47(4), 407-423. https://doi.org/10.1080/09571736.2019.1610033

Venezky, R. L. (1990). Definitions of literacy. In R. L. Venezky, D. A. Wagner \& B. S. Ciliberti, B. S. (Eds.), Toward defining literacy (pp. 2-16). International Reading Association. https:// repository.upenn.edu/literacyorg_chapters/10

Wisniewska, N., \& Mora, J. (2020). Can captioned video benefit second language pronunciation? Studies in Second Language Acquisition, 42(3), 599-624. https://doi.org/10.1017/ S0272263120000029

Watanabe, Y. (2006). Japanese people watching subtitled Japanese-language TV shows: Function or aesthetic? Japan Studies Review, X, 19-30. https://asian.fiu.edu/projects-and-grants/ japan-studies-review/journal-archive/volume-2006/watanabe-subtitled-final.pdf 